Öztürk E Kazanasmaz, 2018

Volume 4 Issue 3, pp. 43-59

Date of Publication: 16th November, 2018

DOI-https://dx.doi.org/10.20319/mijst.2018.43.4359

This paper can be cited as: Öztürk, Y., E Kazanasmaz, Z. T. (2018). Work Characterıstıcs, Vısual and Energy Needs in Office and Factory Lighting. MATTER: International Journal of Science and Technology, 4(3), 43-59.

This work is licensed under the Creative Commons Attribution-Non Commercial 4.0 International License. To view a copy of this license, visit http://creativecommons.org/licenses/by-nc/4.0/ or send a letter to Creative Commons, PO Box 1866, Mountain View, CA 94042, USA.

\title{
WORK CHARACTERISTICS, VISUAL AND ENERGY NEEDS IN OFFICE AND FACTORY LIGHTING
}

\author{
Yasemin Öztürk \\ Department of Architecture, Izmir Institute of Technology, İmir, Turkey \\ yaseminozturk@iyte.edu.tr \\ Zehra Tuğçe Kazanasmaz \\ Department of Architecture, Izmir Institute of Technology, Izmir, Turkey \\ tugcekazanasmaz@iyte.edu.tr
}

\begin{abstract}
The visual effect of lighting effects health and comfort conditions of a working place. Lighting design requirements are based on the function of spaces. Healthy and comfortable work spaces increase user motivation, mentally support them, improve concentration and physically decrease accidents. Lighting strategies applied to the offices are arranged according to working hours and needs of the user, while they are needed to be implemented more systematically in factories than the offices due to the industrial characterization including task types, machines/equipment, etc. Working styles influence the lighting strategies. The purpose is to prevent the undesired reflection from the computer screen in offices, while it is essential to provide an environment that decreases the work accidents in industrial buildings. Color rendering index is a vital issue to determine the reality sense of color mostly necessary for reading tasks in offices. Energy requirements can be lower by LED technologies in factories and by auto controlled systems in the open plan offices to apply appropriate daylighting plan. So, working time, working style,
\end{abstract}


color rendering index and energy benefits are discussed regarding two workspaces, offices and factories, comparatively. Such a comparison can contribute to literature in terms of indicating key design considerations in two distinctive work spaces.

\section{Keywords}

Lighting, Office, Factory, Visual Comfort

\section{Introduction}

Lighting design becomes an essential concern while considering the architectural needs since people spend most of their daily life at work. It is a part of physical health and affects job performance. A well-planned lighting design provides the user visual health. The appropriate interior design increases users' motivation, mentally support them. It helps to focus on the job (Zumtobel- The Lighting Handbook, 2013). Thus, two main working areas, open plan offices and factories are considered as an issue and discussed on their needs and improvement options for the lighting design.

Evaluation of the lighting design regarding meeting the expectations of the target values and design needs should be made by lighting design highlights. The primary goals of the lighting design provide visually comfortable surroundings, improving the performance of the lighting systems, and meeting with the spatial requirements of the architectural design (Kundurac1, 2017; IESNA, 2000).

Few studies about open plan office and factory lighting are presented according to these criteria with their results. A case study examined the ideal office lighting, using types of lighting controls to accomplish energy efficiency (Maleetipwan-Mattsson \& Laike, 2015). It questioned how visual comfort met requirements for its users. Field estimations completed in eighteen single-inhabitance workplaces with six different lighting controls. Inhabitance and daytime hours were crucial issues for deciding the light use. For every office, inhabitance designs, utilisation of a ceiling luminaire, energy consumption and impression of office lighting in the different seasons were set up. Results showed that the usage rate of luminaires fluctuated among the tenants and could be continual (Maleetipwan-Mattsson \& Laike, 2015).

Another study focused on effectiveness at factories (Grinbergs, 2013). The review expected to assess factory energy use designs and the potential for their change. Existing electrical systems at manufacturing factories were old and there was a time for renewing. Changing over 
customary electrical elements to smart technologies was an essential step in energy consumption. The emphasis on change of existing lighting systems had the capability of being a primary temporary activity to lower the costs.

A researcher from Russia worked on factories' modern and energy efficient lighting (Bogatishchev, 2014). The financial objective was to decrease the energy spent on lighting and exploring the best way to update the system.There was insufficient light prompted laziness and the ability to focus and causes weakness as indicated. Every one of these impacts hurt employment execution, decrease work performance, and adversely affect well-being in the work environment.

Providing a visual comfort for the user is related to optical performance and depending on that, increases the efficiency at work and preserves the eye health. Optimum visual comfort conditions can be achieved by an appropriate lighting design that responds physical and psychological needs of the user (Avci and Beyhan, 2017; IESNA, 2000). Then, to optimise the energy performance, the solutions are derived from the working times and possible sources that can be obtained during these hours.

\section{Offices and Factories as Places to Work}

Both offices and factories are the places where people spend almost half of their time during a day. For this reason, it is desired to make these spaces convenient for the users' needs and comfort. A well-designed working area helps to increase productivity. Therefore, these two places working time, styles, color rendering characterization and energy needs are compared.

\subsection{Working Time}

Firstly, the working hours can be the concern before discussing the lighting design of workplaces. While the offices are used during the daytime, the factories are mostly occupied for work 24 hours a day. This aspect directs the general lighting strategies of these two spaces separately. Nowadays office lighting strategies commonly focused on daylighting design. Daylight combines to the auto-controlled lighting systems at the required times. These programs gradually improve as first examples that seen in Fig. 1, Norman Foster's Commerzbank building in 1997. This case a prototype of auto controlled lighting systems (Shrift, 2010).

In Commerzbank building, the impact of the natural light on the inside of the building on the working quality and productivity were calculated. Details in both the exterior facade and 
interior space arrangements were developed to make use of daylight abundantly at working hours (Shrift, 2010). For example, the partition panels separating office departments were made of transparent materials. This makes the corridors get daylight during the daytime. The building's unique geometry, interior gardens, and atrium are significant to collect more daylight inside the building to illuminate workplaces naturally.

Standard lighting and ceiling systems were applied in the building, especially in the office floors. Linear lighting was installed in a $1.5 \mathrm{~m}$ x $2.25 \mathrm{~m}$ grid system that can be used as night time illumination under the suspended ceiling. In addition to this scheme, well-lighted areas were considered using light and reflective colors on surface finishing. High illuminance and fluorescent lamps help to emphasize the space at the free plan offices.
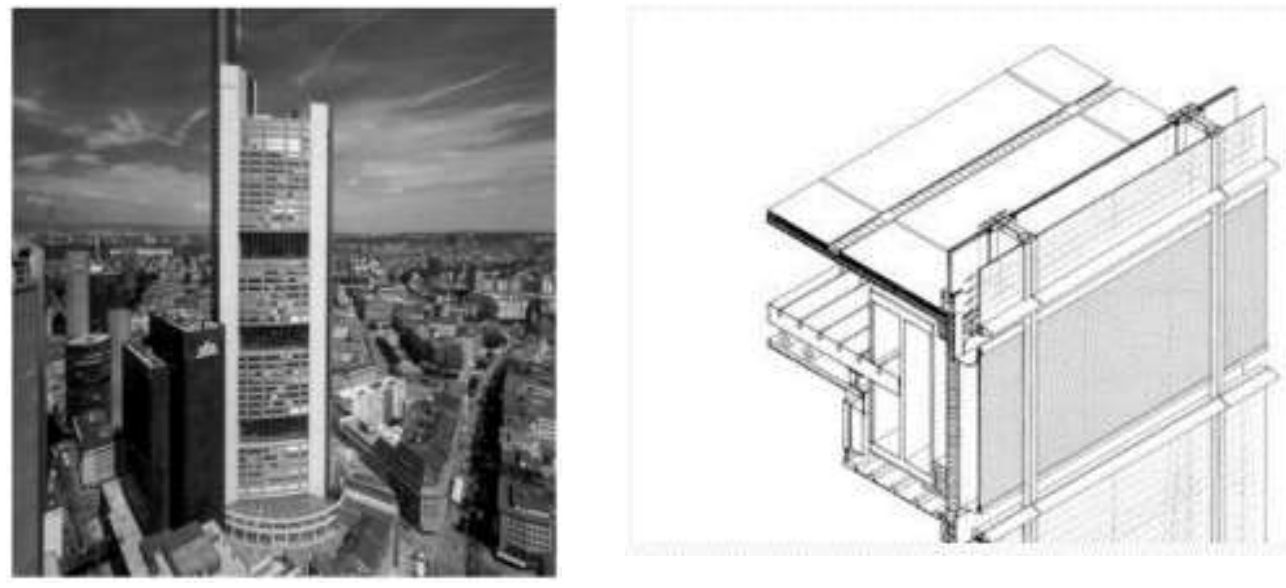

Figure 1: Daylight design of Commerzbank (Shrift, 2010)

Auto-controlled lighting strategies have been improved rapidly over the last decade (Alsat, n.d.). Dimmable lighting fixtures are arranged according to daily user plans and their luminance needs.

Energy saving methods are applied in auto-controlled lighting systems. First of all, in the architectural project, designs are prepared which can make maximum use of the daylight of the building, and can make the most use of daylight from the living spaces. Even the lighting channels that transmit the light comes to the outside ceiling of the building can be utilized. Productive, long-lasting and economical lighting products that provide the required minimum light intensity to the desired area can be chosen for the intended use of the space. Then, with the lighting control system in turn: 
- Motion - Control with Entity Detector (Determining whether the place is in use or not, closing the light after a given period)

- Time Program Control (Automatic control of fittings without the need for human intervention according to the usage time of the place, vacation and shift hours.)

- Control by Light Intensity (Depending on the light coming from the window at different points of the place, some luminaires can be turned on and off to provide equal illumination at every corner of the room)

- Combined Control (Combination of different control types for maximum efficiency) (Alsat, n.d.)

Lighting strategies applied to the offices are arranged according to working hours and needs of the user. Similar lighting schemes are valid for the factory lighting,as well. However, the lighting strategies are needed to be implemented more systematically than the ones in offices. The reason why this is getting complicated than the offices is that, the industrial characterization including task types, machines/equipment, etc. of the factories requires different visual adaptation and needs while the new technologies and machinery are in use of the production facilities (Fig. 2) (Lee \& Kim, 2012). The factory lighting designs are carried out according to the full day (24h) working time conditions. Motion-control in lighting systems can have a stronger influence on systems' energy efficiency in factories than in offices because of the former's operation in the whole day. Daylight implemented controls can be much better in offices due to the daytime occupancy. At the case presented by Lee and Kim, auto controlled rotational lighting system is designed to provide the required quantity of light to the related part of the machine (Lee \& Kim, 2012).
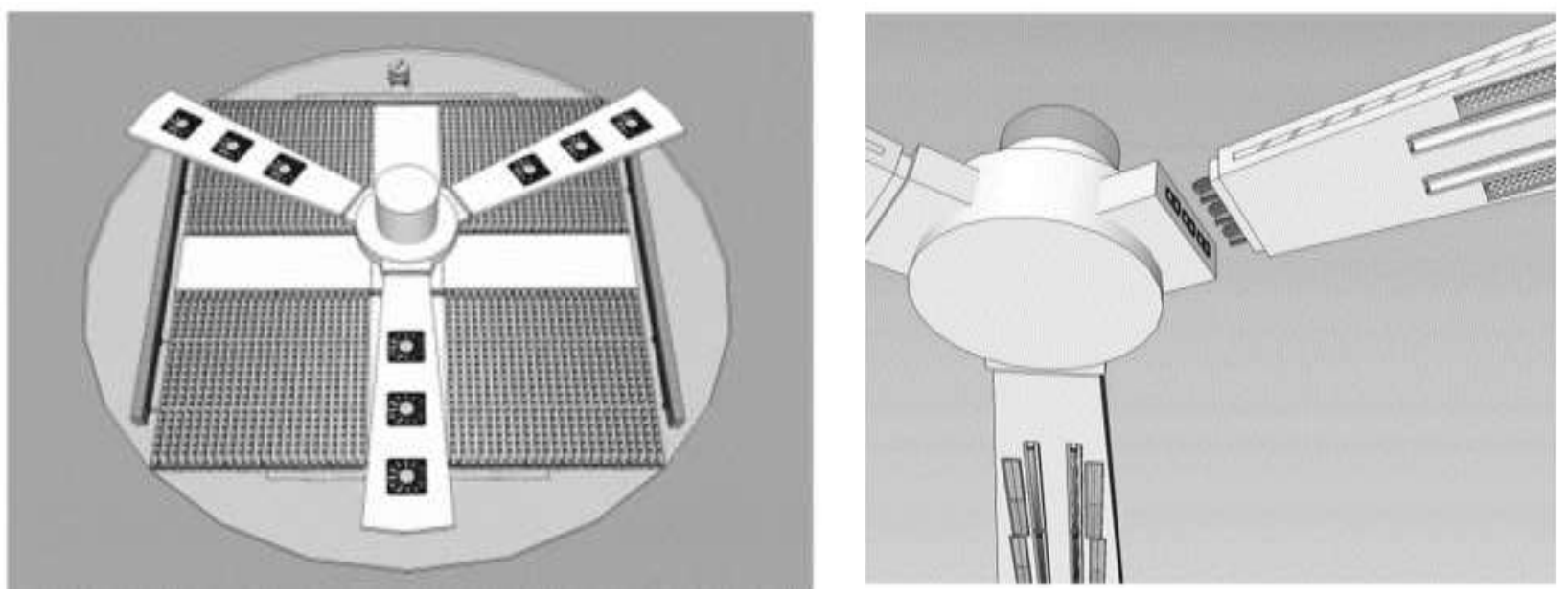
Figure 2: A concept design for smart lighting control system, adapting new technologies to the lighting design of factory (Lee \& Kim, 2012)

\subsection{Working Styles}

Secondly, working styles are useful in considering the lighting strategies of these places. While the primary task is executed either by the computers or by reading, diffuse lighting systems such as cove lighting placement (Fig. 4) and light shelves becoming a great solution for the offices. The purpose of lighting design in the office environment is to prevent the reflection of the computer screen. For this reason, lower illumination may be sufficient when compared to factory lighting.

It is essential to provide an environment that decreases the work accidents in industrial buildings. For this reason, high illumination levels are recommended in factories and workshops. These values vary from 300 lux to 2000 lux (Table 1). In such a well-lighted environment, the aim is to prevent the task being done under veiling effect or shadowing area. In this way, the visual acuity is increased. The work surface against work accidents should be well illuminated. Having a dynamic of daylight in offices improves concentration and keeps a person alert. So, daylight aids a healthy attitude to work. As daylight is a very powerful light source, lower values of daylight are found to be enough for tasks in offices.

Table 1: Recommended illumination levels according to activity types (Grondzik \& Kwok, 2014)

\begin{tabular}{|l|l|l|}
\hline \multirow{4}{*}{$\begin{array}{l}\text { Industrial and } \\
\text { General }\end{array}$} & Activity Types & Recommended Illumination Levels \\
\cline { 2 - 3 } Engineering & Heavy Machine Assembly & 300 lux \\
\cline { 2 - 3 } & Spot welding & 300 lux \\
\cline { 2 - 3 } & Tool shops & $500-1000$ lux \\
\cline { 2 - 3 } & Inspections and Testing & $300-750$ lux \\
\cline { 2 - 3 } & Wind Tunnels & $500-2000$ lux \\
\hline \multirow{3}{*}{ Offices } & General offices & 100 lux \\
\cline { 2 - 3 } & Drawing offices & 500 lux \\
\cline { 2 - 3 } & Executive offices & 500 lux \\
\cline { 2 - 3 } & Computer workstations & $300-500$ lux \\
\hline
\end{tabular}




\begin{tabular}{|l|l|}
\hline Filling rooms & 300 lux \\
\hline Print rooms & 300 lux \\
\hline CAD design areas & $300-500$ lux \\
\hline Drawing boards & 750 lux \\
\hline
\end{tabular}

Special tasks are observed in industrial areas (Fig. 3). Each task has to have its significant lighting consideration. One lighting scheme for a task may require low-angle lighting to make the worker concentrate on the irregularities on a surface, while the other has to avoid specular reflection on the task area on a diffuse background (Philips, 1993).Sometimes directional lighting is necessary to reveal the form and texture of the object at hand.

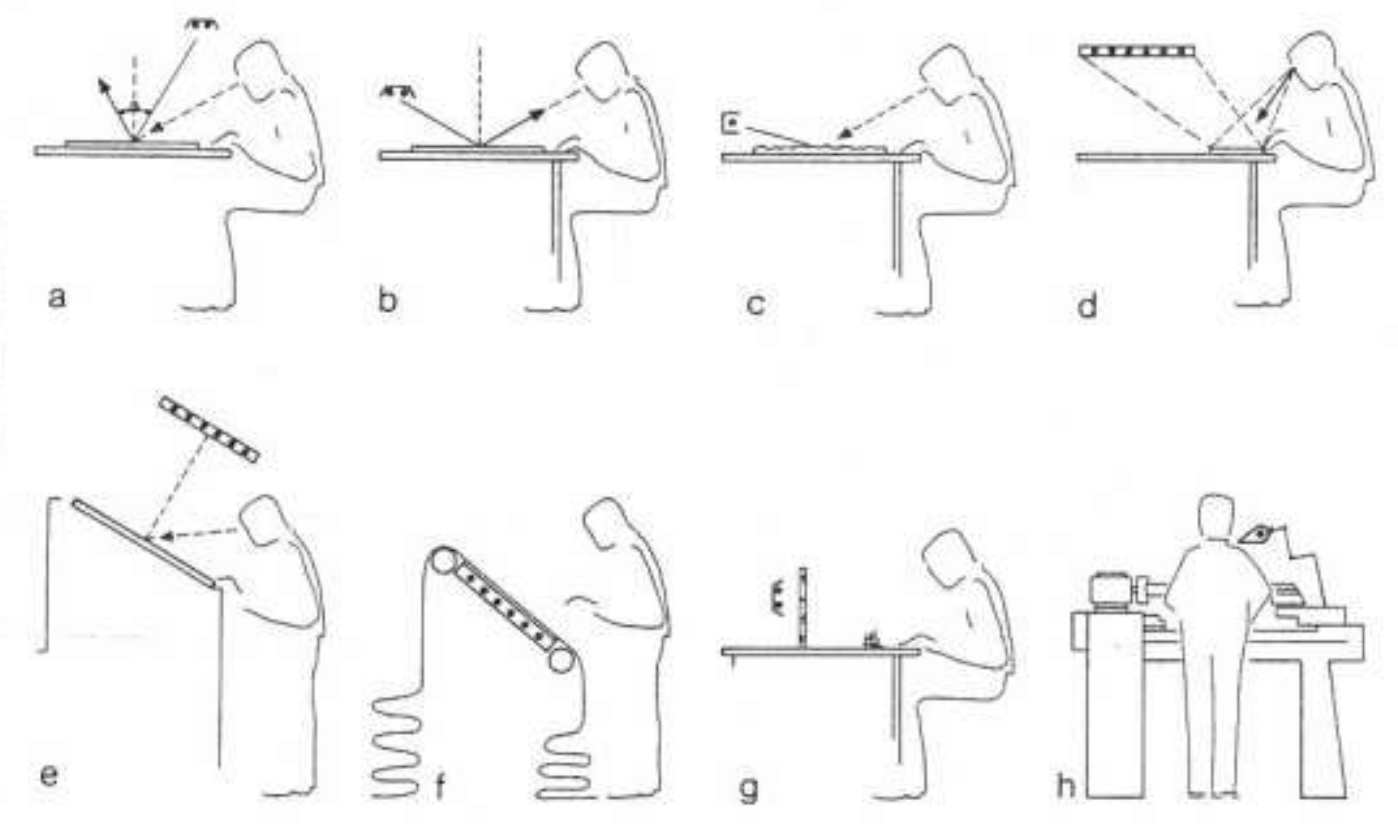

Figure 3: Industrial lighting variations according to task type (Philips, 1993)

Large spaces with enormous ceiling heights (4m-7m-higher) in industry require high mounting heights for luminaires which are still in use in the daytime. Narrow-beam luminaires are recommended for general lighting when the machinery is tall and located very closely. So, the floor can be illuminated without obstructions caused by machinery. Wide-beam luminaires can be suitable to illuminate vertical surfaces clearly.

As today's daily office routine, people spend time both on the phone, in front of computer screen and on reading, writing facilities. All of these tasks have their own lighting requirements. 
So, the interior environment required to meet these needs as well as creating pleasant surroundings.

Working plane which is approximately $0.80 \mathrm{~m}$ above the floor is the general task area important at the offices. Recommended luminance at the task area is $100-300 \mathrm{~cd} / \mathrm{m}^{2}$ (Philips, 1993). The uniformity ratio should be higher than 0.8 at the general lighting of open plan offices. Improving the lighting conditions of the workplace increases not only individuals' creativity but also the productivity of group. Favorable conditions allow for improved performance and wellness of the worker helps to reach the concentration levels higher than normal. The architects plan to decrease eye fatigue, the reduction of possible errors due to poor lighting and achieve better results than casual (Fig. 4). It is, therefore, clear that a proper and careful planning of work areas both allow the achievement of a functional results and increases the wellbeing of the worker (Durak, Camgöz Olguntürk, Yener, Güvenç, \& Gürçınar, 2007).
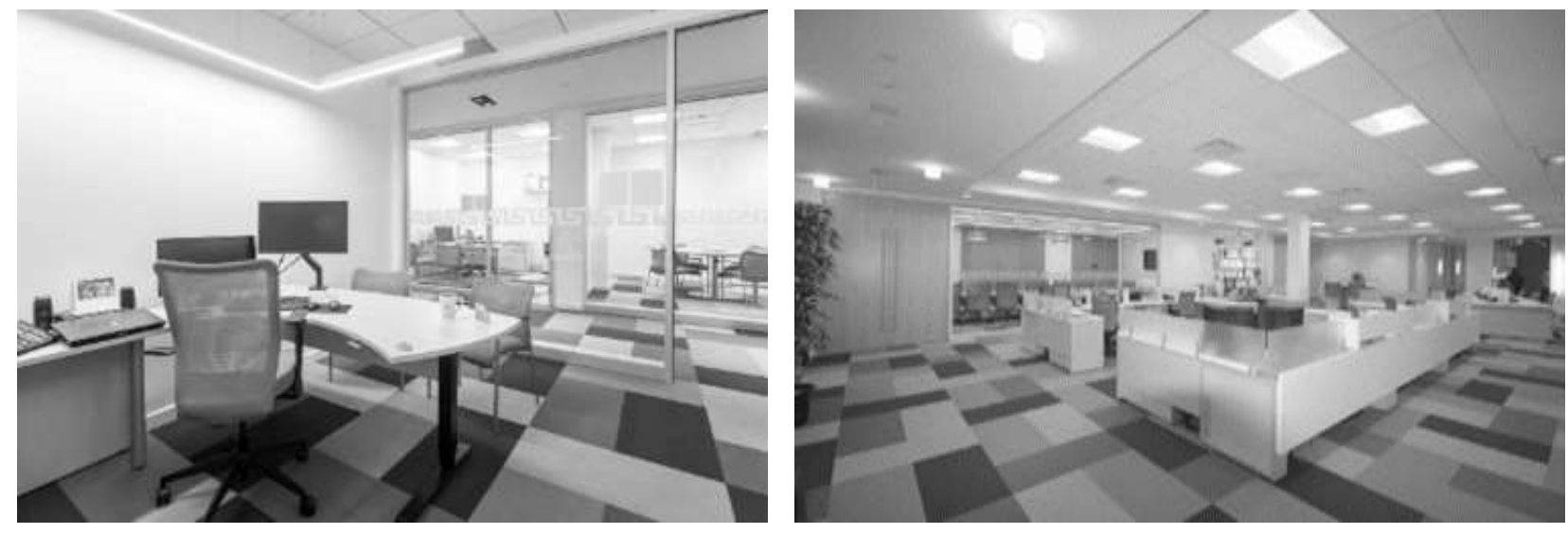

Figure 4: An individual office designed to evaluate general lighting and cove lighting-open plan office lighting design ("LED lighting shows versatility in office project (Magazine) - LEDs," n.d.)

Opposite to that, the factories have specialized machines or workers, and their production results are the primary goal of the work (Fig. 5). So, the individual focal lighting systems and, focused - high luminance are required for the factories. 

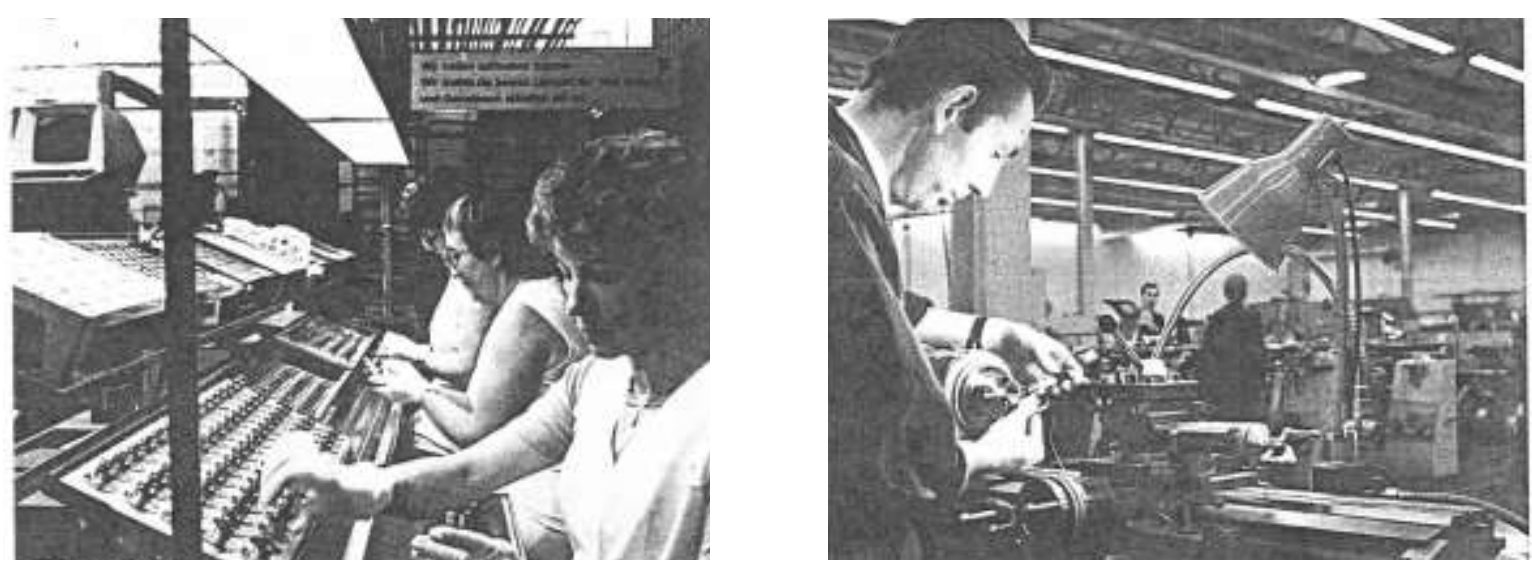

Figure 5: General lighting and focal lighting placement of individuals'(Philips, 1993)

\subsection{Color Rendering Index}

A color rendering index (CRI) is a numeric measure of the capacity of a light source to show the object's color(International Electrotechnical Commission., 1987). CIE general color rendering index is a precise measurement tool to understand the ability of a light source to reveal surface colors precisely. This content depends on the precision with which the analyzed light imitates an arrangement of test colors on how they are replicated by a proper standard light source culminate agreement being given an estimation of 100 (CIBSE, 2002). CRI of fluorescent lamps ranges from 60-90; while, it is around 40 for low-pressure sodium lamps and 65-80 for metal halide lamps.

Color rendering index is a vital element to determine the reality sense of color. For this reason, color rendering index is to be arranged according to the aim of the spaces (Dangol et al., 2013; Erdem \& Demir, 2013).

CIE standards recommend a color rendering range from 80 to 90 of a proper color judgment for individual tasks in factories. For instance, in the food industry, hygiene is the main principle of the production, and one way to provide a clean space is seen the exact colors of the objects.

Open plan offices involve reading and writing facilities as well as computer studies. The ideal color rendering group for reading and computer studies is $60-80$. The primary objective is creating a moderate color rendering to the officers (Zumtobel- The Lighting Handbook, 2013).

\subsection{Energy Needs}

Next issue focuses on the energy needs of offices and factories. This aspect primarily related to the working hours in a day. Since offices are being occupied during the daytime, their 
energy needs can be dramatically decreased by effective daylighting strategies. As the job is carried out by reading, the daylight from the north is going to be a great solution for the offices. It has a diffuse directionality, correspond to a natural source quality and it has the potential of being controlled against glare. In the application of this point, the atrium designs are a common solution to get the daylight to the inside of the building.

Passive daylight systems are practical tools to lower the energy needs. Technically complex systems, regarding light transmission and redirection, perform better than traditional methods (Kunduraci \& Kazanasmaz, 2016). Light shelves are used to direct daylight towards the ceiling and transmit it to the rear parts of the offices (Fig. 6). Their positions can be changed respond to the sun throughout the year (Maleetipwan-Mattsson \& Laike, 2015; Ruck, 2000). Prismatic systems operate according to the principle of transmission of the light through the fenestration system. Daylight is directed towards the ceiling or transmitted to the rear area. They are applicable on the roof and roof openings as well. Light directive glasses are placed between double glazing. These glasses reflect the direct daylight to the lower or higher elevations according to the seasons. They are applied on the façade and the roof, prevent the visual link between inside and outside (Kunduracı \& Kazanasmaz, 2016)

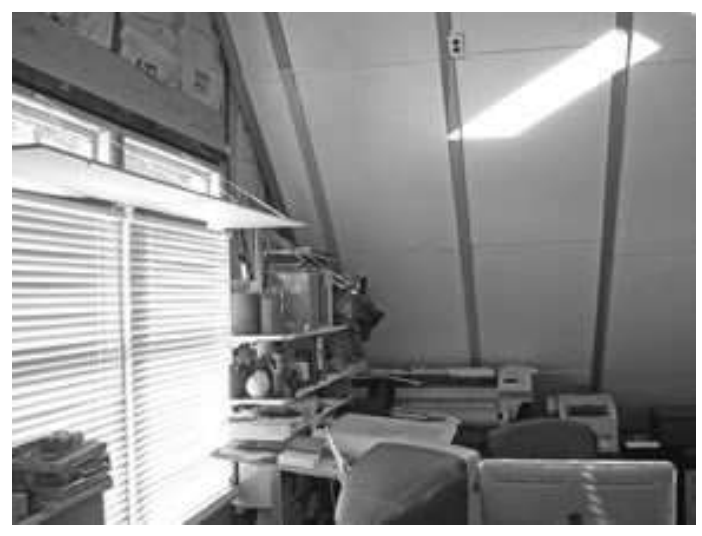

Figure 6: Light shelves at offices(“Daylighting Systems | www.educate-sustainability.eu,” n.d.)

Saving energy spent on lighting systems is essential when planning, designing and operating the building whole energy systems("Production Division:Sengoku works. Ltd.," n.d.). If the amount of the electricity consumed in modern buildings is taken into consideration, energy saving has become a significant concern in illumination. Using light sources with high luminous efficiency and suitable luminaires achieve passive energy conservation. 
Lighting design in the office spaces supports the internal arrangement. Different work and recreation areas need different lighting considerations, such as differentiation in the local areas and serving the needs of various users(Kohn \& Katz, 2002).

General comfort effect is provided with direct lighting, reflected lighting, lighting contrasts of the surfaces, and color characteristics at workplaces. However, lighting should not be at the same level at offices. Providing only uniform illumination both tiring and difficult to understand the reality. Visual environmental items such as lighting intensity, surrounding surfaces, illumination difference between the sections must be examined to generate local distinctions. Lighting tools, and glare, dominant colors in the environment must be checked.

Energy efficient lighting design in factories can be achieved by considering some variables. Primary ones are selection of artificial lighting system, choice of lamps, devices, and competing tools. Height of placement of devices and maintenance factor are essential factors to be considered. At the same time, the factories as they need an enormous amount of energy for 24 hours. So, the lighting elements are selected from the best energy efficient ratio and extended lamp life. For this reason, the compact fluorescent lights are an effective solution to the factories since their both color rendering index is defined in high quality and their efficiency ratio changes between 50-70 percent (Halsted, 1993).

On account of effectively LED innovation, industrial facilities able to impressive energy saving because their payback period of installation is short. LED lighting systems can be utilized adaptably. Various lenses types, dark and light colors, and lumen options are the basics of the custom lighting system for different applications in industry. If the lighting condition needs ought to change after some time, LED systems can be modified and adapted to the newest considerations. These qualities make the LED lights a particularly maintainable arrangement(TAUERO, n.d.).

Energy consumptions are an essential item for redesigning a lighting plan. If the daylight and motion sensor change are used, up to 75 percent energy reserve funds can be accomplished which have a short payback period (Alsat, n.d.)(TAUERO, n.d.).Ballast can be coordinated and taken out whenever without additional devices. This plug-play standard gains up to 50 percent of installation time. LED system can stand to overheating so that and resist more than $50{ }^{\circ} \mathrm{C}$ (TAUERO, n.d.). Furthermore, the LED system is assembled to give at least 60000 hours' lamp life. 
To sum up, the LED technology both at factories and offices provides:

- Savings on energy consumption

- Easy maintenance quality

- Easy to change the lighting plan (flexibility)

- Auto control and dimming qualities

- Preventing overheating at the workplaces

- Accurate controlling

- Reaching higher luminance flux values, up to $4000 \mathrm{~lm}$

- Time-saving installation options

\section{Lighting Characteristics of Offices and Factories}

Enforcing environments require durable solutions at the factories. LEDs made from durable materials can withstand excessive vibration and do not flash or vibrate like glass bulbs. Long service life provides excellent light for years. Factory lighting elements should be durable and easy to maintain because they all have specialized machinery systems installed on large areas. These lamp types should not be an essential part to increase the interior temperature since products have to be produced to some extent. The artificial lighting apertures have to be constant even the vibration or any other physical effect comes to them from the machinery or production system. They need to be placed in the system which is not created shades on production bands or inner-outer canals of machines (Bogatishchev, 2014).

Open plan office lighting solutions help to generate a flexible work environment when there are people with very different activities and characters in one place. Open-plan office lighting provides a pleasant, motivating workspace and make occupants more productive.Their integration with daylight systems area advised. As the lighting fixtures release additional heat to the environment, they should not force the limits of cooling loads and should not disturb the office users. Their arrangement should not cause glare, especially on boards and monitors. When the lighting system designed flexible, the interior layout can be adaptable easily to the new seating plans for further needs.

Glare exists directly or indirectly. Light source can be placed indirectly in the field of vision or line of sight to prevent direct glare. Using several low-intensity lamps in place of few high-intensity lamps and placing fluorescent tubes at right angles to the line of sight other ways 
to solve direct glare. Conversely, avoiding from using reflective colors and materials such as bright metal glass, glossy paper is primary way to control indirect glare. Use surfaces that diffuse light, such as textured finishes, nonglossy surfaces, flat paint and providing several low-intensity lamps in place of few high-intensity lights and use indirect lighting are additional ways to prevent indirect glare (Tooley, 2009).

The lighting design of both factory and open plan offices should be checked about unified glare rating (UGR) to prevent glare (Table 2). UGR is a method to find out the physiological glare and regulated within EN 12464 standards.

Table 2: Unified glare rating limits according to activity types(Zumtobel- The Lighting Handbook, 2013)

\begin{tabular}{|l|c|}
\hline Activity types & $\begin{array}{c}\text { UGR limits that must not } \\
\text { be exceed }\end{array}$ \\
\hline Technical drawing & $\leq 16$ \\
\hline Reading, writing, training, meetings, computer-based work & $\leq 19$ \\
\hline Craft and light industries & $\leq 22$ \\
\hline Heavy industries & $\leq 25$ \\
\hline Railway platforms, foyers & $\leq 28$ \\
\hline
\end{tabular}

Daylighting, artificial lighting, and lighting supportive architectural details compared for the offices and factories. The first concern is the application of the daylighting strategy details to the buildings. Light shelves, light chimneys, and reflective applications are the popular suggestions that allow to the daylight to come interiors in the appropriate way at the offices. However, daylight is not desired for the specific working areas in factories, since it does not stay constant during the day. As changing sky conditions in the seasons affect the production process, daylighting strategies are possible to be considered the office, entrance, circulation and eating facility areas of the factories.

Regarding artificial lighting in offices, auto controlled lighting systems are necessary to make a switch between natural and artificial lighting systems. Such applications might support the participants' visual comfort. In detail, user control is found to be successful in literature. Occupants expressed that, they found the existing daylight level adequate despite the measured daylight level was under the recommendation for the auto control system(Konis, 2013). As 
another concern, the factory lighting design focuses on particular artificial lighting solutions considering energy, lamp lives, maintenance of the system and high-quality color renderings.

\section{Conclusion}

Comparing the relationship between work spaces and their specific needs according to the working environment requirements and task types, following remarks can be summarised.

- Appropriate lighting strategies both provide ergonomic conditions by uniting office and workstation lighting arrangements and lessen energy consumption by no less than an extra 25 percent.

- While arranging working spaces' lighting design, it is necessary to develop strategies upon to the lighting needs of the task and working hours.

- Task applications, spatial qualities, employee needs and working hours are different factors on selecting lighting plans.

- Lighting strategies should be carried on the specific needs of their users.

- Energy requirements can be lower by LED technologies at factories and by auto controlled systems at the open plan offices to apply appropriate lighting plan.

- As the number of lamps increases, investing in those that last longer and more efficient is the right choice.

- In particular, for lightweight, brittle fittings and apertures inside, the weight of the lamp can be a major factor in decision making.

- In individual applications, low-voltage halogen lamps, partly spotlights are suitable for illuminating desired specific locations.

- The setting switch saves energy in standard incandescent lamps through mode adjustment (dimming).

- Choosing the cheapest light does not save money in the long run. Because the lifetime of the lamp is ten times higher than that the artificial lighting, the cost of lighting energy is ten times greater than the cost of purchasing the light.

- Lamps with high efficiency (lumen/watt), long life and low heat flow drop over time can be preferred.

Both office and factory lighting design strategies have some similar considerations such as energy demands, work place's comfort and safety regulations by designing an appropriate indoor 
environment, yet they also have base differentiations on regulating different needs of users. By considering those aspects, research limitations include a quantitative data comparison that supports the findings of that paper and it may include a simultaneous energy consumption calculation and a lighting questionnaire among users of the work places on a case study selected from open office and factory spaces. So scope of future researches may cover relevance between literature remarks and in place measurement related to comfort satisfaction questionnaire

\section{References}

Alsat, C. (n.d.). Aydınlatma Otomasyonu ve Enerji Tasarrufu Sistemleri. EMO Yayınları. Avci, Ali Berkay, and Gülin Ş. Beyhan. 2017. "Achieving A Sustainable City Image in Terms of Twenty-Four Hour City Principles: Case of the Kemeralt1 Bazaar of Izmir, Turkey.” Matter: International Journal of Science and Technology 3(1): 193-209.

Bogatishchev, V. (2014). Improving the Effectiveness of Industrial Lighting. Metallurgist, 58(5/6), 454-458. https://doi.org/10.1007/s11015-014-9932-0

CIBSE. (2002). Code for lighting. Oxford; Boston : Butterworth-Heinemann, 2002.

Dangol, R., Islam, M. S., Hyvärinen, M., Bhusal, P., Puolakka, M., \& Halonen, L. (2013). User acceptance studies for LED office lighting: Preference, naturalness and colourfulness. Lighting Research and Technology, 1477153513514424.

Daylighting Systems |www.educate-sustainability.eu. (n.d.). Retrieved December 27, 2016, from https://www.educate-sustainability.eu/kb/content/daylighting-systems

Durak, A., Camgöz Olguntürk, N., Yener, C., Güvenç, D., \& Gürçınar, Y. (2007). Impact of lighting arrangements and illuminances on different impressions of a room. Building and Environment, 42(10), 3476-3482. https://doi.org/10.1016/j.buildenv.2006.10.048

Erdem, T., \& Demir, H. V. (2013). Color science of nanocrystal quantum dots for lighting and displays. Nanophotonics, 2(1), 57-81.

Grinbergs, K. (2013). Energy efficient electricity usage and lighting solutions for industrial plants. In Civil Engineering. International Scientific Conference (Vol. 4). Jelgava (Latvia): Latvia University of Agriculture.

Grondzik, W. T., \& Kwok, A. G. (2014). Mechanical and electrical equipment for buildings. John Wiley \& Sons.

Halsted, C. P. (1993). Brightness, Luminance, and Confusion. Information Display, 9(3), 21-24. Retrieved from http://www.crompton.com/light/index.html 
IESNA, L. H. (2000). Reference and application volume. New York: Illuminating Engineering Society of North America.

International Electrotechnical Commission. (1987). Vocabulaire electrotechnique international. Chapitre 845 : Eclairage : Vocabulaire international de l'éclairage = International electrotechnical vocabulary. Chapter 845, Lighting: International lighting vocabulary. Bureau Central de la Commission Electrotechnique Internationale.

Kohn, A. E., \& Katz, P. (2002). Building type basics for office buildings. John Wiley \& Sons.

Konis, K. (2013). Evaluating daylighting effectiveness and occupant visual comfort in a side-lit open-plan office building in San Francisco, California. Building and Environment, 59, 662-677. https://doi.org/10.1016/j.buildenv.2012.09.017

Kunduracı, A. C., \& Kazanasmaz, T. (2016). Aydınlatma Kontrol Sistemlerinin Kullanıcı Memnuniyeti Üzerindeki Etkisine Eleştirel Bir Bakış. CBU J. of Sci, 12(3), 553-560. https://doi.org/10.18466/cbayarfbe.280727

Kunduraci, Arzu Cilasun. 2017. "Lighting Design for the Aging Eyes.” MATTER: International Journal of Science and Technology 3(3).

LED lighting shows versatility in office project (Magazine) - LEDs. (n.d.). Retrieved January 2, 2017, from http://www.ledsmagazine.com/articles/iif/print/volume-2/issue-8/features/ledlighting-shows-versatility-in-office-project-magazine.html

Lee, W.-S., \& Kim, S.-G. (2012). Development of rotational smart lighting control system for plant factory. World Academy of Science, Engineering and Technology, 62, 741-744.

Maleetipwan-Mattsson, P., \& Laike, T. (2015). Optimal office lighting use: a Swedish case study. Facilities, 33(9/10), 573-587.

Philips. (1993). Lighting Manual. Netherlands.

Production Division:Sengoku works. Ltd. (n.d.). Retrieved December 28, 2016, from http://www.sengokujp.co.jp/english/business/seihin/index.html

Ruck, N. C. (2000). Daylight in buildings : a source book on daylighting systems and components. Washington, D.C. : International Energy Agency, c2000.

Shrift, J. (2010). ENVS 664-660 Sustainable Design 10/21/2010 Project: Green Buildings Commerzbank Tower. Sustainable Design.

TAUERO. (n.d.). Seeing Better. LED Lighting for Industrial Buildings.

Tooley, M. (2009). Design engineering manual. Elsevier. 
Zumtobel- The Lighting Handbook. (2013) (4th ed.). Retrieved from http://www.zumtobel.com/PDB/teaser/EN/lichthandbuch.pdf 